\title{
Fear of Covid-19 in patients with obesity and the influence on bariatric surgery rates
}

\author{
Mehmet Celal Kizilkaya ${ }^{1, \star}$, Erkan Somuncu ${ }^{1}$
}

\author{
${ }^{1}$ University of Health Sciences, Kanuni \\ Sultan Süleyman Training and Research \\ Hospital, General Surgery, Istanbul, \\ Turkey
}

\section{*Correspondence}

drmckizilkaya@gmail.com

(Mehmet Celal Kizilkaya)

\begin{abstract}
Introduction: In this study, we aimed to examine and compare the effect of fear of Covid-19 disease on the lives of obese individuals and the effect of this fear on bariatric surgery rates, and the state of fear and anxiety in operated individuals. Materials and Methods: A total of 568 eligible patients were recruited for the study. The patients were screened for age, sex, body mass index (BMI), having bariatric surgery history, comorbidities and Covid-19 symptoms and diagnosis. The patients were evaluated for fear of Covid-19 with the Fear of Covid-19 Scale (FCV-19S). Results: A total of 568 patients were included in this study. The mean age of the female patients was $49.71 \pm$ 12.35. The mean age of the male patients was $40.38 \pm 9.38$. Of the patients, 208 (36.6\%) were male, while $360(63.4 \%)$ were female. There were significantly more patients with a bariatric surgery history and at least one Covid-19 symptom were (39.3\%) than patients with no bariatric surgery history $(20.9 \%)(P<0.05)$. Patients with a BMI lower than 50 $\mathrm{kg} / \mathrm{m}^{2}$ had significantly higher FCV-19S scores $(P<0.05)$. Conclusion: The population with the highest BMI may show less fear of Covid-19, according to FCV-19S. This kind of behaviour (fear, anxiety, etc.) may be seen as an effect of disregard. Obese populations should be treated by psychiatrists and should be educated about obesity and Covid-19.
\end{abstract}

\section{Keywords}

Fear; Coronavirus; Covid-19; Bariatric surgery; Fear scale; Obesity

\section{Introduction}

Starting from the last quarter of 2019, the world has been shaken by the impact of the novel coronavirus (Covid-19) and the severe respiratory complications associated with it. Coronavirus has instantly become a global health emergency, as announced by the World Health Organization (WHO). The most commonly encountered symptoms of Covid-19 are fever, dry cough, fatigue, myalgia and respiratory distress [1]. The virus has an incubation period of 5 to 14 days [1]. The rapid and wide spread and mortality risk of the virus have led to intense fear among both younger and older populations. Anxiety and fear among infected patients have been previously reported [2]. Anxiety, depression and fear are known to have some effects on immunity [3]. Researchers worldwide are currently working to develop antiviral drugs and effective vaccines while relying on social distancing and self-isolation $[1,4]$. Furthermore, it is important to consider future anxiety, depression, fear and psychological diseases related to Covid19 [3].

The morbidity and mortality of Covid-19 are subject to the comorbidities of the patient [5]. The most common comorbidities are hypertension, coronary artery disease, diabetes and respiratory diseases. Renal diseases and cancer are rare comorbidities [6-11].
Obesity is a fast-spreading health issue that has been described as a disease by the WHO. Obesity incidence is expected to grow further during a pandemic because of the long quarantine times. With the increase in obesity, comorbidities also increase, which is also related to Covid-19 morbidity and morbidity. In this study, we aimed to investigate the fear of Covid-19 in patients with obesity, the association of Covid-19 with comorbid diseases and how the fear is affected by bariatric surgery.

Obesity brings risks, which are very important in terms of Covid-19. The metabolic syndrome caused by obesity raises these risks.

The incidence of diseases such as hypertension and diabetes, which is one of the underlying causes in the severe course of Covid-19 disease and even death, is quite higher in obese individuals compared to the normal population. This increases the rates of Covid-19 disease to be severe and even death in obese individuals.

In the light of this information, in this study, we aimed to examine and compare the effect of fear of Covid-19 disease on the lives of obese individuals and the effect of this fear on bariatric surgery rates, and the state of fear and anxiety in operated individuals. 
TA B L E 1. Fear of coronavirus-19 Scale (FCV-19S).

Strongly Disagree Neither Agree Agree Strongly

Disagree

nor Disagree

Agree

I am most afraid of coronavirus-19.

It makes me uncomfortable to think about coronavirus-19.

My hands become clammy when I think about coronavirus-

19.

I am afraid of losing my life because of coronavirus-19.

When watching news and stories about coronavirus-19 on social media, I become nervous or anxious.

I cannot sleep because I'm worrying about getting coronavirus-19.

My heart races or palpitates when I think about getting coronavirus-19.

TA B L E 2. Demographic information $(\mathbf{N}=568)$.

\begin{tabular}{|c|c|c|c|}
\hline & & Min-Max & Mean \pm SD \\
\hline \multirow[t]{2}{*}{ Age (years) } & & $20-69$ & $40.59 \pm 11.35$ \\
\hline & & $\mathbf{N}$ & $\%$ \\
\hline \multirow{2}{*}{ Sex } & Female & 360 & 63.4 \\
\hline & Male & 208 & 36.6 \\
\hline \multirow{2}{*}{ Age Group } & $<50$ years & 448 & 78.9 \\
\hline & $\geq 50$ years & 120 & 21.1 \\
\hline \multirow{2}{*}{ BMI Group 1} & $<45$ & 464 & 81.7 \\
\hline & $\geq 45$ & 104 & 18.3 \\
\hline \multirow{2}{*}{ BMI Group 2} & $<\mathbf{5 0}$ & 536 & 94.4 \\
\hline & $\geq \mathbf{5 0}$ & 32 & 5.6 \\
\hline \multirow{2}{*}{ Operation } & Yes & 224 & 39.4 \\
\hline & No & 344 & 60.6 \\
\hline \multirow{3}{*}{ Comorbid Disease } & Yes & 152 & 26.8 \\
\hline & No & 416 & 73.2 \\
\hline & $* * 1$ & 104 & 68.4 \\
\hline \multirow[t]{2}{*}{ Comorbid Disease $(n=152)$} & $* * 2$ & 40 & 26.3 \\
\hline & $* * 3$ & 8 & 5.3 \\
\hline \multirow{2}{*}{ Covid-19 Symptom } & Yes & 160 & 28.2 \\
\hline & No & 408 & 71.8 \\
\hline \multirow{3}{*}{ Covid-19 Symptoms $(\mathrm{n}=160)$} & $* 1$ & 144 & 90 \\
\hline & $* 2$ & 8 & 5.0 \\
\hline & $* 4$ & 8 & 5.0 \\
\hline \multirow{2}{*}{ Covid-19 Diagnosis } & Yes & 8 & 1.4 \\
\hline & No & 560 & 98.6 \\
\hline
\end{tabular}

*The numbers indicating how many covid-19 symptoms individuals contains which mentioned in the material and method section $(1,2,4)$. **Numbers indicating how many comorbid diseases exist.

\section{Materials and methods}

Ethical approval was taken from local committee from Kanuni Sultan Süleyman Training and Research Hospital with number
KSSEAH-Q0420-2020. A total of 568 eligible patients were recruited for the study. The inclusion criterion was patients with a BMI of 30 or more. The exclusion criteria were lacking written consent of the patient and patients younger than 18 
TA B L E 3. Evaluation of the characteristics of patients on the basis of previous bariatric surgery.

\begin{tabular}{lcccc}
\multicolumn{1}{c}{ Patient Properties } & \multicolumn{3}{c}{ Operation } & $\boldsymbol{P}$ \\
& & Yes $(\mathbf{n}=\mathbf{2 2 4})$ & No $(\mathbf{n}=\mathbf{3 4 4})$ & \\
Sex & Female & $128(59.3 \%)$ & $88(40.7 \%)$ & $\boldsymbol{P}<\mathbf{0 . 0 0 1 *}$ \\
& Male & $96(27.3 \%)$ & $256(72.7 \%)$ & \\
Age Group & $\mathbf{5 0}$ years & $208(46.4 \%)$ & $240(53.6 \%)$ & $\boldsymbol{P}<\mathbf{0 . 0 0 1 *}$ \\
& $\geq \mathbf{5 0}$ years & $16(3.3 \%)$ & $104(86.7 \%)$ & \\
Comorbid Disease & Yes & $72(47.4 \%)$ & $80(52.6 \%)$ & \multirow{0}{*}{$\mathbf{0 . 0 1 9 *}$} \\
& No & $152(36.5 \%)$ & $264(63.5 \%)$ & \\
Comorbid Diseases $(\mathbf{n}=\mathbf{1 5 2})$ & $* * \mathbf{1}$ & $48(46.2 \%)$ & $56(53.8 \%)$ & \\
& $* * \mathbf{2}$ & $24(60 \%)$ & $16(40 \%)$ & - \\
& $* * \mathbf{3}$ & - & $8(100 \%)$ &
\end{tabular}

${ }^{*} P<0.05, * *$ Numbers indicating how many comorbid diseases exist.

years old. Informed consent was obtained from all individual participants included in the study. The patients were screened for age, sex, body mass index (BMI), comorbidities and Covid19 symptoms and diagnosis. All patients were evaluated for fear of Covid-19 with the Fear of Covid-19 Scale (FCV19S) (Table 1). The FCV-19S contains seven questions with answers ranging from 1 to 5 degrees of agreement (strongly disagree, disagree, neither agree nor disagree, agree, strongly agree), resulting in a final score between 7 and 35 .

Comorbid diseases such as hypertension, diabetes mellitus, respiratory diseases, hyperlipidemia and coronary heart disease that were increased by obesity were questioned and recorded.

Considering symptoms such as fever, dry cough, fatigue, myalgia and respiratory diseases as Covid-19 symptoms, patients with one or more of them were tested with paranasal and pharyngeal swabs, RT-PCR, and those with positive results were recorded.

Individuals who had elective bariatric surgery due to obesity were recorded. The pre-operative BMI, presence of the above-mentioned comorbid diseases, the presence of Covid-19 symptoms and whether the disease was diagnosed, and FCV19S score were recorded.

\subsection{Statistical analysis}

Statistical analysis was performed with IBM SPSS version 22.0 statistical package (IBM SPSS, Türkiye). The distribution of continuous variables was assessed for normality using normal probability curves with the Kolmogorov-Smirnov test and was presented as the means with standard deviations (SD) or medians with interquartile ranges (IQRs). Qualitative variables were analysed with the Pearson chi-square test. Quantitative variables between the two groups were analysed with Student's $t$ test. Recurrent measurements were analysed with the paired sample $t$ test.

Statistical significance was $P<0.05$.

\section{Results}

A total of 568 patients were included in this study. The mean age of the female patients was $49.71 \pm 12.35$. The mean age of the male patients was $40.38 \pm 9.38$. Of the patients, 208 patients $(36.6 \%)$ were male, while $360(63.4 \%)$ were female. The demographic characteristics of the participants are presented in Table 2. A total of 448 patients $(78 \%)$ were under age 50. A total of $104(18 \%)$ patients had a BMI over 40 $\mathrm{kg} / \mathrm{m}^{2}$. Of the patients, $32(5.6 \%)$ had a BMI greater than 50 $\mathrm{kg} / \mathrm{m}^{2}$, and $224(39.4 \%)$ had a bariatric surgical history.

A total of 416 patients (73.2\%) had no comorbidity, 152 $(26.8 \%)$ had at least one comorbidity, and $160(28.2 \%)$ had at least one Covid-19 symptom, with $90 \%$ having only one symptom. Eight patients (1.4\%) were diagnosed with Covid19.

Females had significantly higher bariatric surgery rates $(P$ $<0.05$ ) (Table 3). The rate of having had bariatric surgery (46.4\%) was found to be significantly higher in those under $50(13.3 \%)(P<0.05)$ (Table 3). The rate of having had bariatric surgery $(47.4 \%)$ in patients with comorbidities was significantly higher than that in patients without comorbidities (36.5\%) $(P=0.019 ; P<0.05)$ (Table 3$)$.

There were significantly more patients with a bariatric surgery history and at least one Covid-19 symptom (39.3\%) than patients with no history of bariatric surgery $(20.9 \%)(P$ $<0.05$ ) (Table 4).

$39.4 \%$ of patients were operated on due to obesity. FCV19s score was $21.54 \pm 6.86$ on average in patients undergoing surgery due to obesity.

There was no difference between patients with a history of bariatric surgery and patients with no history of bariatric surgery on the FCV-19S $(P>0.05)$ (Table 5).

Patients younger than 50 years old had significantly higher Covid-19 fear scale scores than older patients $(P=0.002 ; P<$ 0.05 ) (Table 6). Patients with a BMI lower than $50 \mathrm{~kg} / \mathrm{m}^{2}$ also had significantly higher FCV-19S scores $(P<0.05)$ (Table 6). Patients with no comorbid disease had higher FCV-19S scores than patients with comorbidities $(P<0.05)$ (Table 6$)$.

\section{Discussion}

The FCV-19S is a stable and straightforward test that has strong psychological properties [3]. High FCV-19S scores are high in proportion to the severity of Covid-19 fear [3]. 
TA B L E 4. Covid-19 evaluations on the basis of previous bariatric surgery.

\begin{tabular}{|c|c|c|c|c|}
\hline \multicolumn{2}{|l|}{ Covid-19 Evaluation } & \multicolumn{2}{|c|}{ Operation } & $P$ \\
\hline \multirow{4}{*}{ Covid-19 Symptom } & & Yes $(n=224)$ & No $(n=344)$ & \multirow{4}{*}{$P<0.001 * *$} \\
\hline & Yes & $88(39.3 \%)$ & $72(20.9 \%)$ & \\
\hline & No & $136(60.7 \%)$ & $272(79.1 \%)$ & \\
\hline & $* 1$ & $72(81.8 \%)$ & $72(100 \%)$ & \\
\hline \multirow{2}{*}{ Covid-19 Symptoms $(\mathrm{n}=160)$} & $* 2$ & $8(9.1 \%)$ & - & \multirow[t]{2}{*}{ - } \\
\hline & $* 4$ & $8(9.1 \%)$ & - & \\
\hline \multirow{2}{*}{ Covid-19 Diagnosis } & Yes & $8(3.6 \%)$ & - & \multirow{2}{*}{ - } \\
\hline & No & $216(96.4 \%)$ & 344 (100\%) & \\
\hline
\end{tabular}

*The numbers indicating how many covid-19 symptoms individuals contains which mentioned in the material and method section $(1,2,4)$. ${ }^{* * P} P<0.05$.

\begin{tabular}{|c|c|c|}
\hline \multirow[t]{2}{*}{ Surgery } & \multicolumn{2}{|c|}{ Fear of Covid-19 Scale } \\
\hline & Min-Max & Mean $\pm \mathbf{S D}$ \\
\hline Yes $(n=224)$ & $7-35$ & $21.54 \pm 6.86$ \\
\hline No $(n=344)$ & $7-35$ & $21.05 \pm 8.34$ \\
\hline Total & $7-35$ & $21.24 \pm 7.79$ \\
\hline$t$ & 0.762 & \\
\hline$P$ & 0.446 & \\
\hline
\end{tabular}

Many studies from the literature have reported that anxiety and fear of infectious epidemic diseases are related to people's well-being [12-14]. It is important to treat and support psychologically disturbed people in times of pandemic, when everybody is confused and focused on the disease [3]. Common comorbidities associated with poor prognosis are hypertension, respiratory diseases, cardiac diseases, pregnancy, renal diseases and malignancies [15-19]. Studies have shown that comorbidities are associated with higher Covid-19 incidence and worse prognosis [5].

Obesity rates and related metabolic conditions have risen globally over the past few decades [20].

Due to the alarming rate of increase in Covid-19, lockdowns may create stressful situations for people who remain cooped up at home for long hours. This situation can potentially result in increased food consumption due to boredom or even stress eating behaviour, which will increase the rates of obesity and comorbidities [21, 22].

Palaiodimos et al. [23] reported that severe obesity is independently associated with higher in-hospital mortality and, in general, worse in-hospital outcomes in patients with Covid19.

In the literature, it is clearly stated that low-grade chronic systemic inflammation, common in people with obesity, is associated with the development of atherosclerosis, type 2 diabetes, and hypertension, well-known comorbidities that adversely affect the outcomes of patients with Covid-19 [24].

Cai et al. [25] reported in their study that obese patients had increased odds of progressing to severe Covid-19, and as the severe acute respiratory syndrome coronavirus may continue to spread worldwide, clinicians should pay close attention to obese patients and carefully manage such cases with prompt and aggressive treatment.

Obesity is a metabolic disease that is associated with comorbidities. Fear of Covid-19 can peak to pathological levels in the obese population, leading to psychological diseases. Psychotherapy is essential for these patients.

Our more than one-quarter of our patient group (26.8\%) had at least one comorbidity. Of these patients, nearly half had a history of bariatric surgery. While $28.2 \%$ of the patients had at least one Covid-19 symptom, only $1.4 \%$ had been diagnosed with Covid-19. Interestingly, healthier patients with fewer or no comorbidities had higher fear scale scores. However, there was no significant difference between obese patients on the basis of having had bariatric surgery.

Our study has limitations such as not including information about the educational status of the patients, and not comparing the FCV-19S scores of patients who underwent surgery during the pandemic and those who did not decide for bariatric surgery. With the permission of the Ministry of Health, the demand for bariatric surgery has increased by $30 \%$ when the number of patients applying to the polyclinic is considered. With the permission of the Ministry of Health to obesity surgeries during the pandemic, a basis for these comparisons will be formed.

\section{Conclusions}

The population with the highest BMI may show less fear of Covid-19, according to FCV-19S. In our study, we found that obese patients older than 50 years old with at least one comorbid disease had significantly lower FCV-19S scores and bariatric surgery incidence. This kind of behaviour may be seen as an effect of disregard. These obese patients should be treated by psychiatrists and should be educated about obesity related diseases.

\section{ABBREVIATIONS}

BMI, Body mass index; Covid-19, Coronavirus disease 2019; FCV-19S, Fear of Covid-19 Scale; WHO, World Health Organization. 
TA B L E 6. FCV-19S evaluations on the basis of BMI, comorbidities and age groups.

\begin{tabular}{|c|c|c|c|c|}
\hline & & $\begin{array}{c}\text { Covid-19 Fear Scale } \\
\text { Mean } \pm \text { SD }\end{array}$ & $t$ & $P$ \\
\hline \multirow{2}{*}{ Age Group } & $<50$ years & $21.82 \pm 7.35$ & \multirow{2}{*}{3.104} & \multirow{2}{*}{$0.002 *$} \\
\hline & $\geq 50$ years & $19.07 \pm 8.95$ & & \\
\hline \multirow{2}{*}{ BMI Group 1} & $<\mathbf{4 5}$ & $22.05 \pm 7.32$ & \multirow{2}{*}{4.800} & \multirow{2}{*}{$P<0.001 *$} \\
\hline & $\geq 45$ & $17.62 \pm 8.76$ & & \\
\hline \multirow{2}{*}{ BMI Group 2} & $<\mathbf{5 0}$ & $21.72 \pm 7.55$ & \multirow{2}{*}{6.166} & \multirow{2}{*}{$P<0.001 *$} \\
\hline & $\geq \mathbf{5 0}$ & $13.25 \pm 7.48$ & & \\
\hline \multirow{2}{*}{ Comorbid Disease } & Yes & $18.00 \pm 7.09$ & \multirow{2}{*}{-6.431} & \multirow{2}{*}{$P<0.001 *$} \\
\hline & No & $22.42 \pm 7.70$ & & \\
\hline
\end{tabular}

$* P<0.05$.

\section{ETHICS APPROVAL AND CONSENT TO PARTICIPATE}

Ethical approval was taken from local committee from Kanuni Sultan Süleyman Training and Research Hospital with number KSSEAH-Q0420-2020.

\section{AUTHOR CONTRIBUTIONS}

Study concept and design: M.C.K., acquisition of data: M.C.K., analysis and interpretation of data: M.C.K., E.S., Preparation of study tools: M.C.K., Drafting of manuscript: M.C.K., Critical revision: E.S.

\section{ACKNOWLEDGEMENTS}

Thanks to all the peer reviewers and editors for their opinions and suggestions.

\section{FUNDING}

The author declares no conflict of interest and source funding.

\section{CONFLICT OF INTEREST}

The authors declare that they have no conflict of interest.

\section{INFORMED CONSENT}

Informed consent was obtained from all individual participants included in the study.

\section{ADDRESS FOR REPRINTS}

Kanuni Sultan Süleyman Training and Research Hospital, General Surgery Clinic, Kucukcekmece/Istanbul, Turkey.

\section{REFERENCES}

[1] Wang D, Hu B, Hu C, Zhu F, Liu X, Zhang J, et al. Clinical characteristics of 138 hospitalized patients with 2019 novel coronavirusinfected pneumonia in Wuhan, China. Journal of the American Medical Association. 2020; 323: 1061-1069.
[2] Lin CY. Social reaction toward the 2019 novel coronavirus (Covid-19). Social Health and Behavior. 2020; 3: 1-2.

[3] Ahorsu DK, Lin CY, Imani V, Saffari M, Griffiths MD, Pakpour AH. The fear of Covid-19 scale: development and initial validation. International Journal of Mental Health and Addiction. 2020: 1-9.

[4] Dong L, Hu S, Gao J. Discovering drugs to treat coronavirus disease 2019 (Covid-19). Drug Discoveries \& Therapeutics. 2020; 14: 58-60.

[5] Guan WJ, Liang WH, Zhao Y, Liang HR, Chen ZS, Li YM, et al. Comorbidity and its impact on 1590 patients with Covid-19 in China: a nationwide analysis. European Respiratory Journal. 2020; 55: 2000547.

[6] Huang C, Wang Y, Li X, Ren L, Zhao J, Hu Y, et al. Clinical features of patients infected with 2019 novel coronavirus in Wuhan, China. The Lancet. 2020; 395: 497-506.

[7] Chen N, Zhou M, Dong X, Qu J, Gong F, Han Y, et al. Epidemiological and clinical characteristics of 99 cases of 2019 novel coronavirus pneumonia in Wuhan, China: a descriptive study. The Lancet. 2020; 395 : 507-513.

[8] Wang D, Hu B, Hu C, Zhu F, Liu X, Zhang J, et al. Clinical characteristics of 138 hospitalized patients with 2019 novel coronavirusinfected pneumonia in Wuhan, China. Journal of the American Medical Association. 2020; 323: 1061-1069.

[9] Liu K, Fang YY, Deng Y, Liu W, Wang MF, Ma JP, et al. Clinical characteristics of novel coronavirus cases in tertiary hospitals in Hubei Province. Chinese Medical Journal. 2020; 133: 1025-1031.

[10] Xu XW, Wu XX, Jiang XG, Xu KJ, Ying LJ, Ma CL, et al. Clinical findings in a group of patients infected with the 2019 novel coronavirus (SARS-Cov-2) outside of Wuhan, China: retrospective case series. British Medical Journal. 2020; 368: m606.

[11] Fang L, Gao P, Bao H, Tang X, Wang B, Feng Y, et al. Chronic obstructive pulmonary disease in China: a nationwide prevalence study. The Lancet Respiratory Medicine. 2018; 6: 421-430.

[12] Duncan LA, Schaller M, Park JH. Perceived vulnerability to disease: development and validation of a 15 -item self-report instrument. Personality and Individual Differences. 2009; 47: 541-546.

[13] Pappas G, Kiriaze IJ, Giannakis P, Falagas ME. Psychosocial consequences of infectious diseases. Clinical Microbiology and Infection. 2009; 15: 743-747.

[14] Ropeik D. The consequences of fear. EMBO Reports. 2004; 5: S56-S60.

[15] Shiley KT, Nadolski G, Mickus T, Fishman NO, Lautenbach E. Differences in the epidemiological characteristics and clinical outcomes of pandemic (H1N1) 2009 influenza, compared with seasonal influenza. Infection Control \& Hospital Epidemiology. 2010; 31: 676-682.

[16] Booth CM, Matukas LM, Tomlinson GA, Rachlis AR, Rose DB, Dwosh HA, et al. Clinical features and short-term outcomes of 144 patients with SARS in the greater Toronto area. Journal of the American Medical Association. 2003; 289: 2801-2809.

[17] Garbati MA, Fagbo SF, Fang VJ, Skakni L, Joseph M, Wani TA, et al. A comparative study of clinical presentation and risk factors for adverse outcome in patients hospitalised with acute respiratory disease due to MERS coronavirus or other causes. PLoS One. 2016; 11: e0165978. 
[18] Matsuyama R, Nishiura H, Kutsuna S, Hayakawa K, Ohmagari N. Clinical determinants of the severity of middle east respiratory syndrome (MERS): a systematic review and meta-analysis. BMC Public Health. 2016; 16: 1203.

[19] WHO. Clinical management of severe acute respiratory infection when novel coronavirus(nCoV) infection is suspected: interim guidance. 2020; Available at: https://www.who.int/internalpublications-detail/clinical-management-of-severeacute-respiratory-infection-when-novel-coronavirus(ncov)-infection-is-suspected.

[20] Mitchell NS, Catenacci VA, Wyatt HR, Hill JO. Obesity: overview of an epidemic. Psychiatric Clinics of North America. 2011; 34: 717-732.

[21] Cotter EW, Kelly NR. Stress-related eating, mindfulness, and obesity. Health Psychology. 2018; 37: 516-525.

[22] Rundle AG, Park Y, Herbstman JB, Kinsey EW, Wang YC. Covid-19related school closings and risk of weight gain among children. Obesity (Silver Spring). 2020; 28: 1008-1009.

[23] Palaiodimos L, Kokkinidis DG, Li W, Karamanis D, Ognibene J, Arora
$\mathrm{S}$, et al. Severe obesity, increasing age and male sex are independently associated with worse in-hospital outcomes, and higher in-hospital mortality, in a cohort of patients with Covid-19 in the Bronx, New York. Metabolism. 2020; 108: 154262.

[24] Chiappetta S, Sharma AM, Bottino V, Stier C. Covid-19 and the role of chronic inflammation in patients with obesity. International Journal of Obesity(London). 2020: 44:1790-1792.

[25] Cai Q, Chen F, Wang T, Luo F, Liu X, Wu Q, et al. Obesity and Covid19 severity in a designated hospital in Shenzhen, China. Diabetes Care. 2020: 43: 1392-1398.

How to cite this article: Mehmet Celal Kizilkaya, Erkan Somuncu. Fear of Covid-19 in patients with obesity and the influence on bariatric surgery rates. Signa Vitae. 2021;17(1):26-31. doi: $10.22514 /$ sv.2020.16.0104. 